\title{
O MEIO DO CAMPO EM DISPUTA E AS IMPLICAÇÕES DA "NOVA" CLASSE MÉDIA RURAL NA AÇÃO PÚBLICA
}

\author{
THE BATTLE FOR THE MIDDLE FIELD AND THE \\ IMPLICATIONS OF THE "NEW" RURAL MIDDLE CLASS \\ IN PUBLIC ACTION
}

\author{
Denis Soldera \\ Universidade Federal do Rio Grande do Sul - Porto Alegre - RS - Brasil \\ Paulo Andre Niederle \\ Universidade Federal do Rio Grande do Sul - Porto Alegre - RS - Brasil
}

\begin{abstract}
Resumo: Este artigo discute as implicações que as disputas pela classe média rural determinaram à ação pública na última década. Valendo-se de pesquisa documental e bibliográfica, resgata os referenciais que orientaram a trajetória recente das políticas para o meio rural. $\mathrm{O}$ artigo argumenta que, apesar de possuírem origens teóricas e políticas distintas, alguns referenciais privilegiaram justificativas essencialmente agrícolas e produtivistas, convergindo para legitimar a orientação das políticas agrícolas, inclusive daquelas especificamente destinadas à agricultura familiar, para um segmento mais capitalizado de agricultores, a nova classe média rural. Isso ocorreu em detrimento de um olhar mais atento à diversidade e às demais justificativas que poderiam orientar o suporte a outros segmentos.
\end{abstract}

Palavras-chave: Agricultura familiar. Classe média rural. Políticas públicas. Desenvolvimento rural.

\begin{abstract}
This paper discusses the implications for public action of the disputes over the rural middle class in the last decade. Drawing on documentary and bibliographic research, it analyses the recent trajectory of policies for rural areas. It argues that despite different theoretical and political backgrounds, some referentials have privileged agricultural and productivist justifications, converging to legitimize the orientation of policies, even those specifically directed to family farmers, to a more capitalized segment of farmers, the "new" rural middle class. This process occurred at the expense of a closer understanding of the rural diversity, as well as the other legitimate justifications that could guide the public support to other segments.
\end{abstract}

Keywords: Family farming. Rural middle class. Public policy. Rural development.

\section{Introdução}

$\mathrm{Na}$ última década uma quantidade significativa de estudos dedicou-se ao entendimento e à interpretação da chamada nova classe média rural (NERI, MELO e MONTE, 2012; ALVES e ROCHA, 2010; LOPES et al, 2012; PICOLOTTO, 2012; entre outros). Especialmente após a divulgação dos dados do Censo Agropecuário de 2006 (IBGE, 2009), essas análises buscaram explicitar a relevância de um contingente de agricultores situado em um estrato intermediário de renda, o qual teria sido ampliado por um processo de mobilidade social ascendente. Do ponto de vista teórico, a representação emergente do médio produtor rural ressuscitou antigas teses que misturam as teorias marxistas sobre diferenciação social com a já conhecida teoria da modernização (LONG, 2001) ${ }^{1}$. Uma das repercussões desse fenômeno foi o

\footnotetext{
${ }^{1}$ As teorias marxistas (especialmente por parte de Vladimir Lênin e Karl Kautsky) e a teoria da modernização agrícola convergem principalmente na ideia de inviabilidade produtiva da "pequena produção" e no inevitável ocaso do campesinato perante os avanços capitalistas. Os pequenos produtores
} 
questionamento de categorias sociopolíticas que haviam se consolidado no debate acadêmico e político, tais quais agricultura familiar e agronegócio.

$\mathrm{O}$ debate acerca da classe média rural revigorou antigas divergências e também trouxe à tona novos embates (PICOLOTTO, 2015). No centro da discussão está, mais uma vez, a capacidade de reprodução social e permanência no meio rural dos estabelecimentos rurais mais "pobres", ou seja, os "periféricos" (FAO/INCRA, 1994). Algumas teses voltaram a questionar a "vocação agrícola" destes estabelecimentos. Nesse sentido, apontaram para a concentração do Valor Bruto da Produção em uma pequena porção dos estabelecimentos familiares (GASQUES et al., 2010; ALVES e ROCHA, 2010). Por sua vez, as antíteses procuraram refutar a ideia de que o desenvolvimento rural estaria associado somente ao incremento produtivo, ao predomínio da agricultura em larga escala e/ou à lógica da eficiência produtiva e tecnológica (COSTA, 2013; MATTEI, 2015). Ambas as posições passaram a se afrontar enquanto referenciais para a ação pública.

A análise da ação pública proposta neste texto orienta-se em conceitos oriundos da Abordagem Cognitiva, especificamente a partir dos estudos de autores franceses como Pierre Muller, Bruno Jobert e Ève Fouilleux. A principal contribuição dessa perspectiva é compreender o papel das ideias de diferentes atores no contexto em que as políticas públicas são idealizadas e concebidas (MULLER e SUREL, 2004). Ademais, de acordo com Niederle e Grisa (2013, p. 100), essa abordagem tem o mérito de considerar o modo como as representações de mundo e os espaços onde elas acontecem (fóruns e arenas) pautam "as disputas que envolvem a produção de "referenciais de políticas públicas"”.

A ideia de referencial de política pública incorpora o resultado de representações coletivas que visam interpretar e agir sobre determinados problemas sociais. Ainda que possa representar períodos de transição, um referencial corresponde a uma ideia hegemônica que norteia a concepção das políticas públicas (GRISA, 2012). O conceito pode ser decomposto em dois elementos: referencial global e referencial setorial. Enquanto o referencial global extrapola os limites de um setor, abarcando ações e decisões macroeconômicas e políticas de um país, bem como os planos gerais de desenvolvimento, um referencial setorial refere-se às representações de um setor, como agricultura, educação, saúde e outros (GRISA, 2012; MULLER e SUREL, 2004) 2.

No entanto, diferentemente do caso francês no qual essa abordagem foi concebida, no Brasil, nota-se a consolidação de, pelo menos, dois referenciais setoriais distintos para a agricultura. Até 2016, eles estavam institucionalizados em duas estruturas de Estado: Ministério do Desenvolvimento Agrário - MDA, responsável pelo apoio à Agricultura Familiar; e Ministério da Agricultura, Pecuária e Abastecimento MAPA, que coordena um conjunto de instrumentos voltados ao agronegócio

seriam inerentemente atrasados, marginais às relações de trabalho e, portanto, fadados ao desaparecimento. Deveriam ceder lugar ao moderno e a uma agricultura mecanizada e produtiva. Logo, seria pela modernização agrícola que uma minoria de agricultores viabilizaria sua permanência no campo, tornando-se, portanto, modernos e "incorporados" ao capitalismo (LONG, 2001). Conforme estas interpretações, as bases para a inserção capitalista da pequena produção limitam-se na noção clássica de "produção simples de mercadorias", o que resulta na negação da capacidade de reorganização e resiliência dos camponeses frente às transformações impostas pela modernidade capitalista (NIEDERLE, 2009).

2 O referencial de uma política também é influenciado pelas alterações ocorridas no referencial global (desenvolvimentismo, neoliberalismo) que, por conseguinte, também modificam o referencial setorial (agricultura, educação, saúde, indústria). Conforme Grisa (2012, p. 37), "Se o referencial global é alterado, há um movimento na sociedade no sentido de ajustar os referenciais setoriais àquele e, logo, há mudanças nas políticas públicas". 
(SABOURIN, 2007) ${ }^{3}$. Com efeito, o objetivo deste artigo é analisar as implicações que a ascensão política e acadêmica da classe média rural - transgredindo a divisão que se cristalizou entre agricultura familiar e agronegócio - surtiu no ordenamento da ação pública desses ministérios.

Os resultados apontam para o modo como a ideia de classe média embaralha as classificações e fortalece uma nova dualidade, a qual se estabelece não mais entre agricultura familiar e agronegócio, mas entre produtivos e não produtivos. Essa dualidade parece ser funcional à própria legitimação da classe média rural e, mais do que isso, à lógica de segmentação social que o termo propõe, na medida em que os termos do debate se voltam para razões quantitativas de produção e produtividade agrícolas. Assim, sob o pretexto de romper com os maniqueísmos que a cristalização das identidades sociopolíticas estabeleceu na lógica da ação pública, avança-se para novas formas de segregação socioeconômica, cujos efeitos podem ser tão ou mais nefastos do que a dualidade até então predominante. Ademais, volta-se a enfatizar uma representação que reduz o rural a uma lógica eminentemente setorial e produtivista.

\section{Forjam-se os referenciais, forjam-se as interpretações}

A fim de esquematizar a dualidade de referenciais a partir da qual as políticas de desenvolvimento rural são concebidas, é necessário sumariar os principais fatos e vicissitudes ocorridos na trajetória da ação pública, sobretudo no que se refere à relação entre Estado e sociedade. O benefício do tempo nos permite resgatar e compreender o processo que forjou e caracterizou a polaridade de ideias que conduzem às interpretações entre os dois referenciais. Compreender essa trajetória evidencia que as políticas voltadas aos residentes no meio rural brasileiro foram discriminatórias, especialmente no que se refere à inclusão socioprodutiva e à distribuição da renda gerada pelas atividades agrícolas.

Nas primeiras décadas do século passado, o campo brasileiro era caracterizado principalmente pela baixa dinamicidade produtiva, econômica e social. A cafeicultura era o único cultivo agrícola com representatividade na pauta das exportações totais e a organização dos agricultores (exceto dos grandes proprietários de terra) era ainda considerada primitiva e com baixíssima influência política e reivindicatória (NAVARRO, 2015a). A mudança desse cenário inicia na década de 1930, quando a agricultura assume o papel de coadjuvante nos primeiros planos de desenvolvimento. As estratégias iniciadas com o Estado Novo visavam transformar a economia agrárioexportadora (ou tradicional) em urbano-industrial (ou moderna), além de diversificada e capaz de substituir importações. A agricultura passou a ser vista como instrumento funcional ao novo modelo desenvolvimentista (MIELITZ NETTO, 2011).

\footnotetext{
${ }^{3}$ Esta divisão deixou de existir quando o MDA foi extinto pelo governo do presidente interino Michel Temer, o que encerrou abruptamente um esforço de mais de duas décadas de negociações para a estabilização de uma arquitetura institucional para as políticas públicas de desenvolvimento rural. Não faz parte do escopo deste texto analisar os efeitos produzidos por esta ruptura institucional, até mesmo porque a instabilidade e a letargia do Estado neste contexto de transição dificultam qualquer tipo de conclusão. Ademais, este texto foi produzido a partir de reflexões construídas com o olhar para uma dinâmica de disputas sociopolíticas que antecedem esses eventos. Até o momento, o modo como estas disputas repercutirão na nova estrutura do Estado não está totalmente manifesto. Apesar da extinção do MDA, suas atribuições não foram unificadas no MAPA, tal qual demandavam alguns atores políticos. Elas foram inicialmente destinadas ao Ministério do Desenvolvimento Social e, em seguida, repassadas à Casa Civil (BRASIL, 2016; BRASILa, 2016). De todo modo, nota-se a manutenção do mesmo tipo de dualidade, pelo menos no que concerne à existência de diferentes estruturas para tratar do meio rural.
} 
A primeira metade da década de 1960 é especialmente marcada pelo debate das questões agrárias. De acordo com teóricos estruturalistas, a reforma agrária legitimavase pela necessidade de conter os altos índices da inflação. A isso se subentendia a baixa produtividade da agricultura como responsável pelo aumento dos preços dos alimentos e também pelas crises de abastecimento (MIELITZ NETTO, 2011). Contudo, os ideais de reavivar "a grande esquecida da revolução industrial brasileira" (BRESSER-PEREIRA, 2015, pág. 171), logo seriam arrefecidos pelo Golpe Militar de 1964, oriundo de um pacto autoritário-modernizante.

O período pós-1964 até meados dos anos 1980 pode ser considerado o de maior relevância na consolidação do referencial baseado na modernização agrícola. Dentre as principais ideias, ganharam espaço as teorias que apregoavam a funcionalidade da agricultura no processo de crescimento do país, como um dos pilares de sustentação da expansão da indústria interna. Assim, o Estado tomara para si a incumbência de fomentar a produção agrícola como parte de um modelo que consistia em modernizar, urbanizar e industrializar. Convém ressaltar que também havia a necessidade de sustentar os interesses dos setores mais conservadores, como uma classe média urbana e os grandes proprietários de terras (MIELITZ NETTO, 2011; GONÇALVES NETO, 1997).

No entanto, diante de uma agricultura incapaz de dar conta das incumbências que o plano nacional-desenvolvimentista almejava, foi necessário implantar um amplo programa de modernização e a criação de instituições que possibilitassem o aumento da produtividade agrícola. Para Navarro (2015a, p. 55), esta época torna-se relevante porque "o Estado brasileiro implantou uma ousada estratégia nacional de modernização tecnológica das atividades agropecuárias". Tal ousadia, contudo, seria posteriormente caracterizada como a "modernização desigual" ou a "modernização conservadora" (GRAZIANO DA SILVA, 1992).

Em que pesem os resultados positivos obtidos com os avanços na produtividade e modernização da atividade agrícola, a mudança no padrão produtivo e a grande absorção de capital acabaram por penalizar os agricultores de menor tamanho e trabalhadores rurais. Discriminadamente, os planos foram direcionados a determinadas regiões (sul-sudeste), produtos (commodities) e agricultores (grandes). Isso contribuiu para o agravamento da concentração fundiária, esvaziamento do campo e impactos negativos ao ambiente (MIELITZ NETTO, 2011; DELGADO, 2011). Para Filippi (2011, p. 345), ocorreu, nessa década, "uma deteriorização das condições de reprodução social no meio rural nacional".

Até a década de 1980, o Estado adotou uma política agrícola ativa e compensatória e os principais instrumentos eram crédito, seguro agrícola, pesquisa agropecuária, assistência técnica e extensão rural, além de incentivos fiscais e cambiais (DELGADO, 2011). As políticas públicas eram concebidas de forma centralizada e homogênea (GRISA e SCHNEIDER, 2015). Logo, não por acaso, é nessa década que milhares de pessoas, invisíveis aos olhos do Estado e incapazes de melhorar suas condições via produtividade agrícola, emigraram dos campos em direção às periferias urbanas.

Conhecida como a década perdida, os anos 1980 marcaram o início de outra etapa nas políticas de desenvolvimento rural, especialmente em decorrência da forte reorientação macroeconômica. Após dois choques seguidos no preço internacional do petróleo (1973 e 1979), o custo do processo de modernização tornou quase proibitivo seguir a mesma lógica. Por sua vez, a crise internacional da dívida impactou decisivamente as reservas de capital existentes no país e o acesso a recursos internacionais. $\mathrm{O}$ crédito para a agricultura, antes farto, sofreu forte retração. 
Em resposta aos choques adversos, os ganhos em produtividade tornaram-se ainda mais relevantes e necessários, pois a prioridade era equilibrar a balança de pagamentos e controlar a dívida externa. Para isso, segundo Gonçalves Neto (1997), a agricultura deveria produzir alimentos a fim de controlar a inflação; gerar excedentes exportáveis para sustentar a dívida externa e substituir produtos importados para diminuir os gastos com a importação.

As ações de intervenção voltadas ao campo brasileiro estiveram predominantemente subordinadas às decisões e indecisões oriundas da macro orientação político-econômica (MIELITZ NETTO, 2011). Ainda que o Estado tenha atuado na formação de pequenas colônias no sul do país e no favorecimento aos deslocamentos populacionais para o centro-oeste, a importância socioeconômica da agricultura de base familiar sempre foi subsidiária aos interesses da agricultura de larga escala (PICOLOTTO, 2015). Essa situação mudaria com alterações no cenário político e institucional dos anos 1990, alterações que favoreceram o advento de novas interpretações sobre desenvolvimento rural baseadas principalmente em reivindicações de atores que estavam invisíveis às pautas da ação pública.

A reconfiguração do Estado, especialmente a partir da Constituinte de 1988, foi fundamental para que novas ideias, interesses e instituições passassem a nortear, instituir e reivindicar um referencial de desenvolvimento rural alternativo àquele assentado na produtividade da grande lavoura, que orientava majoritariamente as políticas agrícolas até então. A redemocratização iniciada no final dessa década foi determinante para o afloramento de um processo de mudança que resultou, dentre outras conquistas, na legitimação da Agricultura Familiar como categoria sociopolítica representante de outro referencial de desenvolvimento rural. Observa-se o início da dualidade de referenciais em que a ação pública passaria a estar organizada, especialmente a partir do reconhecimento por parte do Estado da diversidade e especificidade do meio rural enquanto público-alvo de políticas. $\mathrm{O}$ reconhecimento da importância da agricultura de base familiar representou o início da institucionalização de demandas distintas daquelas que orientavam as políticas agrícolas e agrárias até essa década.

\section{Dois referenciais de desenvolvimento rural: agronegócio versus agricultura familiar}

Além das transformações nas relações entre Estado e sociedade, a década de 1990 foi marcada pela hegemonia do pensamento neoliberal e pelas tentativas de estabilidade via controle monetário. Sumariamente, o Estado centralizador de outrora foi substituído por um Estado mínimo, imbuído na retórica do livre mercado. Também marcaram essa fase, o acirramento das disputas pela terra e o retorno da questão agrária. Ademais, foram instituídos, finalmente, os direitos previdenciários aos agricultores e também às agricultoras. Não obstante, agravaram-se os conflitos socioambientais (MIELITZ NETTO, 2011; DELGADO, 2011).

Embora a década de 1990 seja marcada por uma grande expansão do agronegócio, consolidando, inclusive, sua presença e influência política, é nesta década que também ganham relevância institucional as reivindicações dos agricultores de base familiar (GRISA e SCHNEIDER, 2015; DELGADO, 2011). Por meio da promulgação da Lei Agrícola de 1991, instituiu-se a categoria Agricultura Familiar como forma de direcionar políticas e ações conforme a heterogeneidade e especificidade dos agricultores de base familiar (MIELITZ NETTO, 2010). 
Picolotto (2015) destaca que o processo de consolidação da Agricultura Familiar enquanto ator sociopolítico resultou da confluência de ideias e interpretações de três conjuntos de atores. $\mathrm{O}$ primeiro grupo corresponde aos intelectuais do meio acadêmico que contribuíram para constituir o campo teórico relacionado ao lugar da agricultura de base familiar nos planos de desenvolvimento. $O$ segundo grupo refere-se a atores ligados às políticas de Estado e normativas legais que propiciaram condições para a oficialização e institucionalização da categoria. Por último, os próprios agricultores familiares, organizados no sindicalismo e em movimentos sociais, foram responsáveis pela difusão e consolidação do reconhecimento da categoria.

Além da institucionalização e reconhecimento da importância sociopolítica da agricultura de menor porte no âmbito da ação pública, representada, sobretudo, pela Lei da Agricultura Familiar (Lei 11.326/2006), merece destaque a "luta simbólica" travada no intuito de reverter os valores negativos atribuídos à agricultura de base familiar. De "atrasado, ineficiente e inadequado", este modelo passou a ser associado a valorações positivas, como "moderno, sustentável e produtor de alimentos" (PICOLOTTO, 2015, p. 65). A legitimação da agricultura familiar, portanto, transpôs os limites formais que antes eram pautados apenas por leis e políticas públicas homogêneas. A categoria passou a abarcar uma nova concepção de desenvolvimento rural e um novo significado frente ao processo de concepção de políticas públicas (ABRAMOVAY, 1998).

Em decorrência disso, em meados dos anos de 1990, verifica-se uma primeira geração de políticas agrícolas e agrárias voltadas à Agricultura Familiar. Constituído à luz dessa ressignificação e conforme condições de reprodução social com base na terra e na produção agrícola, esse conjunto de políticas representou uma confluência de esforços a fim de abarcar demandas e reivindicações que, até então, não direcionavam tais políticas (GRISA e SCHNEIDER, 2015). O Programa Nacional de Fortalecimento da Agricultura Familiar - PRONAF, criado em 1995, tornou-se a primeira ação de relevância direcionada especificamente aos produtores de menor porte e com mão de obra predominantemente familiar. Em seguida, e como decorrência da gestão do PRONAF, destaca-se também a criação de uma Secretaria dentro do MAPA a fim de atender demandas específicas da nova categoria.

O PRONAF visava promover a inserção econômica dos agricultores de base familiar, especialmente no sentido de impulsionar sua capacidade produtiva a fim de integrá-los ao mercado e melhorar a renda (GRISA e SCHNEIDER, 2015). A tipologia discutida pelo modelo teórico proposto pelo convênio Organização das Nações Unidas para a Agricultura e Alimentação - FAO/ Instituto Nacional de Colonização e Reforma Agrária - INCRA, em 1994, teve forte influência no desenho da política pública. O estudo entendia a existência de três tipos de agricultura de base familiar: consolidada, em transição e periférica. Aos consolidados esperava-se manter o apoio financeiro habitual com mecanismos quase privados de crédito. Aos agricultores "em transição" era necessário fomentar a oferta de crédito público, a fim de consolidar sua capacidade produtiva. À categoria periférica seriam destinadas políticas assistenciais e reforma agrária. O PRONAF, portanto, ainda que seja considerado um marco institucional nas políticas voltadas à Agricultura Familiar, foi elaborado com a intenção de atender a demanda dos agricultores "em transição", como forma de incrementar sua capacidade produtiva e torná-los consolidados (PICOLOTTO, 2015). Assim, conforme aponta Mielitz Netto (2011), possivelmente o maior mérito do surgimento do PRONAF reside em sua relevância política para a consolidação da agricultura familiar enquanto públicoalvo de políticas públicas.

Em abril de 1996, após a repercussão do agravamento dos conflitos relacionados à questão agrária, o governo de Fernando Henrique Cardoso criou o Ministério 
Extraordinário de Política Fundiária, que, mais tarde, em 2000, seria transformado no MDA. Ainda que o comando do ministério tenha sido destinado a um político ligado aos movimentos sociais e identificado com partidos de esquerda, o ato em si não representou mudanças substantivas na ação pública. Contudo, teve o mérito de retirar do Ministério da Agricultura as atribuições relativas às questões fundiárias e também o apoio e promoção à agricultura de base familiar (MIELITZ NETTO, 2011).

Uma segunda geração de políticas para a Agricultura Familiar pode ser verificada a partir do final dos anos 1990, quando o Estado neoliberal começou a direcionar ações de viés socioassistencial ao meio rural. São exemplos desse segundo momento as políticas de transferência de renda condicionada, como o Bolsa Escola, Bolsa Alimentação e Auxílio Gás (que mais tarde seriam incorporadas ao Programa Bolsa Família) (GRISA e SCHNEIDER, 2015).

Ainda que a mudança política de 2003 não tenha rompido efetivamente com resquícios dos referenciais anteriores (FONSECA; CUNHA; BICHARA, 2013), esta década marca a consolidação da dualidade em que a ação pública voltada para agricultura passou a ser caracterizada. Especialmente a partir da reestruturação do MDA, passaram a coexistir instrumentos e políticas claramente segmentados entre Agricultura Familiar e a agricultura empresarial. Diante disso, surge um terceiro conjunto de políticas específicas para a Agricultura Familiar, evidenciando o advento de novas pautas e, não obstante, a divergência e o distanciamento institucional de interesses e objetivos entre esses referenciais. Essa terceira geração é marcada, por exemplo, por ideias de atores ligados ao campo da agricultura ecológica e orgânica, estudiosos do mundo rural e organizações da sociedade civil identificadas com o tema da Segurança Alimentar e Nutricional, sustentabilidade e novos mercados para a Agricultura Familiar (GRISA e SCHNEIDER, 2015).

A consolidação do MDA refletiu a transposição da visão dominante que entendia a agricultura somente como um setor produtivista e subsidiário aos planos de desenvolvimento macroeconômicos. No âmbito do Estado, institucionalizou-se o afastamento dessa visão tradicional, produtivista e homogênea e passou-se a reconhecer a heterogeneidade da agricultura, suas peculiaridades e necessidades específicas. Portanto, em contraste à agricultura empresarial de grande escala produtiva, a categoria Agricultura Familiar passou a referenciar outras estratégias de desenvolvimento e também a ser reconhecida "como um modo de vida, portanto, um conceito muito mais rico para dar conta das diversidades (...), merecedoras de reconhecimento, respeito e potencialmente exploráveis pelas políticas públicas." (MIELITZ NETTO, 2010, p. 62).

Ademais, a reestruturação de ambos os ministérios (MDA e MAPA) também evidenciou e consolidou a dualidade ${ }^{4}$ entre os distintos modelos de agricultura. De um lado, o MAPA busca promover o desenvolvimento e a competitividade do agronegócio visando produtividade e competitividade e, por outro, o MDA, já em parceria com o recém-criado Ministério do Desenvolvimento Social e Combate à Fome - MDS, previa ações ao combate da pobreza rural, produção ambientalmente menos degradante, segurança alimentar e nutricional e geração de renda e valor aos agricultores familiares. Em decorrência disso, a necessidade em segmentar o público-alvo dos instrumentos passou a pautar disputas e tensões políticas entre as instituições internas do governo e também entre as organizações sociais e sindicais do campo.

\footnotetext{
${ }^{4}$ É interessante ressaltar que essa dualidade é condizente à condução do próprio governo do presidente Lula. Reflete dois referenciais macroeconômicos e políticos que Erber (2011) assinala como convenções de desenvolvimento. Segundo ele, no governo deste presidente, dois referenciais (ou convenções) coexistiram de forma conflituosa: uma institucionalista mais ortodoxa e outra "neodesenvolvimentista", ambas naturalmente distintas em suas concepções de políticas e ações.
} 
Na década de 2000, o expressivo aumento das exportações de produtos agropecuários, especialmente das commodities, também foi determinante para evidenciar a existência de dois projetos distintos e, em certa medida, divergentes de desenvolvimento rural. $\mathrm{O}$ aumento da produtividade interna e o aumento da demanda de alimentos por países como a China foram os principais fatores que impulsionaram esse processo. Segundo Navarro (2015a), busca-se a consolidação de uma "agricultura moderna" baseada na crescente monetarização das atividades, predomínio do mercado, redução do custo com os trabalhadores ocupados e aumento da utilização dos insumos agroquímicos e agroindustriais.

Assim, ao mesmo tempo em que a demanda da Agricultura Familiar passou a fazer parte dos planos de governo, encontrando inclusive apoio político e institucional, a agricultura empresarial de larga escala também aumentou, de forma ainda mais expressiva e vigorosa, sua influência e sua importância no campo das decisões macroeconômicas e políticas do Brasil. O agronegócio colheu os resultados da mudança produtiva iniciada na década de 1970. Tornou-se inquestionável, portanto, a larga influência desse setor nos campos político e econômico do Brasil, especialmente diante de um sistema presidencialista de coalizões (BRESSER-PEREIRA, 2015).

\section{0 meio do campo em disputa: a emergência do "médio produtor rural"}

Diante de tal polaridade constituída pelos dois ministérios, tensões políticas e divergências acerca das propostas de desenvolvimento rural brasileiro também se tornaram frequentes. Especialmente após a divulgação do Censo Agropecuário de 2006 (IBGE, 2009), no qual a Agricultura Familiar ganhou atenção específica e que evidenciou sua representatividade econômica, social e produtiva, os embates passaram a ser pautados principalmente no campo político e na disputa de um contingente cada vez mais importante de agricultores: a classe média rural.

O Censo Agropecuário de 2006 (IBGE, 2009) apresentou, de forma inédita, um mundo rural dividido em estabelecimentos de base familiar e não familiar. Valendo-se de critérios da recém-promulgada Lei da Agricultura Familiar (Lei 11.326/2006), o IBGE disponibilizou análises específicas à categoria e evidenciou sua representatividade. Imediatamente surgiram críticas e questionamentos acerca dos resultados. Questionou-se o número total de estabelecimentos, a representatividade da Agricultura Familiar frente ao valor bruto produzido e, sobretudo, a participação de um contingente de médios produtores que, segundo os críticos, não deveriam ter sido abarcados pela categoria (CNA/FGV, 2010; ALVES e ROCHA, 2010; NAVARRO, 2010; ALVES, SOUZA e ROCHA, 2012; ALVES e SOUZA, 2015; LOPES et al., 2012).

Por um lado, o MDA, em defesa da categoria e da própria metodologia definida conforme a Lei da Agricultura Familiar, valorizou os resultados divulgados e reforçou a importância do segmento. Por outro lado, representantes do MAPA questionaram os critérios utilizados para classificar os agricultores entre familiares e não familiares. Segundo os mesmos, os dados superestimavam o tamanho e a representatividade da Agricultura Familiar (PICOLOTTO, 2012).

O questionamento à classificação sugeria que os dados divulgados não refletiam a realidade da Agricultura Familiar, pois existiria um grande número de estabelecimentos intermediários identificados com um tipo de agricultura empresarial, tecnologicamente modernizada e integrada ao mercado. Portanto, diferente daquela abarcada e identificada pela categoria da Agricultura Familiar. Ao mesmo tempo, entendiam que a distinção entre familiar e não familiar não dava conta de diferenciar 
os agricultores modernos dos atrasados. Haveria uma diferença, não considerada pelo Censo Agropecuário, entre os agricultores eficientes e integrados ao mercado, e aqueles de mão de obra familiar e que produzem majoritariamente para o próprio sustento. Finalmente, consideravam esse último grupo como uma agricultura atrasada e ineficiente em termos de produção agrícola (PICOLOTTO, 2012).

A fim de ratificar o contraponto levantado pelo MAPA, em 2010, publicou-se uma interpretação diferente dos dados do Censo Agropecuário (CNA/FGV, 2010). Encomendado à Fundação Getúlio Vargas pela Confederação Nacional da Agricultura CNA, a apresentação do documento, escrito por Kátia Abreu (então presidente da CNA), propôs uma classificação diferente, baseada em enquadráveis ao PRONAF e não enquadráveis ao PRONAF (CNA/FGV, 2010). Os resultados do estudo apresentaram uma análise que subestimava os valores divulgados pelo caderno oficial do Censo de 2006 (IBGE, 2009). Segundo os dados da FGV, a Agricultura Familiar (enquadráveis ao PRONAF) abarcaria $64,4 \%$ (e não 84,4\%) do total dos estabelecimentos rurais e seria responsável por $22,9 \%$ (e não $38 \%$ ) do valor bruto da produção agropecuária.

Diante da divergência de interpretações, uma classe intermediária, correspondente à diferença de quase um milhão de agricultores, e responsável pela maior parcela da produção, tornou-se foco de controvertidas análises. Este estrato abarcaria os agricultores parcialmente capitalizados, situados entre os que produzem para autoconsumo e aqueles totalmente integrados ao mercado. A intenção em utilizar o critério "enquadráveis ao PRONAF" e "não enquadráveis ao PRONAF" buscou argumentar que esse número de estabelecimentos rurais não faria parte da Agricultura Familiar e estaria identificada mais com a agricultura empresarial, teoricamente atendida pelas ações do MAPA.

Tanto o MDA como o MAPA passaram rapidamente a direcionar políticas agrícolas a fim de atender esse contingente de agricultores. O MAPA criou o Programa Nacional de Apoio ao Médio Produtor Rural - PRONAMP, linha de crédito voltada ao financiamento do médio produtor rural, cuja lógica socioprodutiva se aproximaria daquela encontrada dentre os "familiares capitalizados". Em 2015, o MAPA também criou uma Secretaria de Interlocução e Mobilidade Social, tendo como responsabilidade elaborar estratégias de ascensão dos agricultores à classe média rural (GLOBO RURALa, 2015). O efeito imediato disso seria a mobilidade de uma parcela de agricultores familiares "produtivos" para a "classe média", saindo do espectro de ação do MDA e passando para o MAPA.

Do outro lado, o MDA agiu para ampliar seu próprio arco de ação, fortalecendo políticas para uma agricultura familiar mais capitalizada. O Programa Mais Alimentos, linha de crédito do PRONAF lançada em 2008, tornou-se a principal política do MDA voltada à modernização da infraestrutura produtiva a fim de incrementar a produção e a produtividade agrícola. De acordo com o Plano Safra 2015/2016 (MDA, 2015e), o Programa Mais Alimentos disponibiliza R $\$ 7$ bilhões para financiamentos de máquinas, implementos e novos equipamentos, com limite variando de $\mathrm{R} \$ 150 \mathrm{mil}$ a $\mathrm{R} \$ 750 \mathrm{mil}$. O volume ofertado representa uma expansão de $20 \%$ em relação ao plano anterior. O volume total de crédito destinando à Agricultura Familiar é de R \$ 28,9 bilhões a taxas de juros variando entre $0,5 \%$ e $5,5 \%$ ao ano.

Na ocasião do lançamento do Plano Safra 2008/2009, referindo-se ao Programa Mais Alimentos, o então presidente Luiz Inácio Lula da Silva afirmou que o Brasil enfrentaria a crise de abastecimento de alimentos com o incentivo à produtividade da Agricultura Familiar. Ao afirmar que "a palavra de ordem é produtividade", o expresidente defendeu a necessidade de transferir tecnologia a esse "segmento produtivo" 
(referindo-se à agricultura de base familiar) por meio da Empresa Brasileira de Pesquisa Agropecuária - Embrapa (MDA, 2015c, p. 1). O objetivo do programa, ressaltado pelo discurso do ex-presidente Lula, seria fomentar a capacidade de produção e oferta de alimentos.

Em relação ao PRONAMP, segundo o Plano Agrícola e Pecuário 2015/2016, o volume de crédito ofertado é de $\mathrm{R} \$ 18,9$ bilhões para custeio e investimento e está voltado aos agricultores que possuem renda bruta anual de até $\mathrm{R} \$ 1,76$ milhão. O limite de financiamento é de $\mathrm{R} \$ 710$ mil para custeio e de $\mathrm{R} \$ 385$ mil para investimento, com taxas de juros entre 7,5\% e 7,75\% ao ano. Em relação ao plano anterior, o volume de recursos ofertado aumentou 17\% (MAPA, 2015e). O PRONAMP também foi tratado como prioridade no plano agrícola de 2015/2016 do MAPA. Um dos seus objetivos, além de ampliar a classe média rural, é absorver parte dos agricultores que atualmente acessam as políticas do PRONAF.

Como parte da estratégia de ampliação da classe média rural, foi conferida elevada prioridade ao objetivo de viabilizar a transição dos produtores familiares para o Pronamp, cujo fortalecimento faz parte das medidas de apoio ao médio produtor rural contidas no Plano Agrícola e Pecuário 2015/16. Nesse sentido, além dos recursos disponibilizados aos agricultores familiares, no âmbito do Pronaf, estes serão parcialmente contemplados, também, com o acesso aos recursos programados para o Pronamp (MAPA, 2015e, p. 23).

Lançado em 2015 pelo MAPA, o programa "Oportunidade: Mobilidade Social no Campo" é outra estratégia do MAPA que busca expandir a classe média rural. Segundo Kátia Abreu, então Ministra da Agricultura, o programa visava aumentar a renda dos pequenos agricultores por meio do apoio à qualificação, extensão rural e estímulo ao associativismo. O "pacote de oportunidades" buscava aumentar a produtividade e a competitividade de aproximadamente 400 mil produtores rurais que se encontram nas classes D e E a fim de incluí-los na classe C até 2018. Para executar o programa, "o governo fará uma busca ativa dos produtores rurais que têm potencial de ascender à classe média" e contará com a parceria de entidades como o Serviço Brasileiro de Apoio às Micro e Pequenas Empresas - SEBRAE (MAPA, 2015; 2015a; 2015b; 2015c).

Ademais, Kátia Abreu defendeu que o MAPA tem prioridade em levar (sic) assistência técnica a 3,7 milhões de propriedades, cuja renda bruta mensal é de até dois salários mínimos, a fim de que esses agricultores possam aumentar a produtividade e ascender socialmente (REVISTA EXAME, 2015). Ampliar a classe média, portanto, "consiste em importante objetivo de nossas políticas públicas", asseverou Abreu (2015a, p. 3). Ainda nas palavras da ex-ministra,

\begin{abstract}
temos de formar uma classe média rural, que no mundo todo é um dos motores da produtividade no campo. Mas, aqui no Brasil, apenas $17 \%$ dos produtores se encaixam nesse perfil. Estamos falando de 3,7 milhões de pequenos proprietários rurais que podem ascender socialmente $-\mathrm{e} o$ caminho para isso passa por dar a eles condições técnicas para que melhorem a rentabilidade de suas propriedades. (...) Penso, por exemplo, em contar com apoio do Sebrae para qualificar as habilidades de gestão dos pequenos produtores, num modelo semelhante ao que é feito com os microempresários urbanos. (REVISTA EXAME, 2015, p. 1)
\end{abstract}

Segundo a British Broadcasting Corporation - BBC Brasil (2015), ao assumir o MAPA, Kátia Abreu recebeu orientação direta da presidente Dilma Rousseff em aumentar a classe média rural. Abreu afirmou ainda que a presidente pediu "obstinação" 
na tarefa de ampliar essa classe e na criação de "programas inovadores" (ESTADÃO, 2016). Em seu discurso de posse, Abreu assumiu a responsabilidade em aumentar a proporção atual de produtores rurais da classe média, conforme orientação macroeconômica. Atualmente, segundo a ex-ministra, $70 \%$ dos produtores encontramse nas classes D/E.

\begin{abstract}
São três os pilares de ação do Mapa: ajudar o setor privado a dispor do enorme excedente de produção acumulado; fazê-lo crescer a taxas elevadas; e ajudar o governo a expandir a classe média. O Mapa é parte do esforço do governo da presidente Dilma para aumentar a classe média, e estamos firmemente empenhados nesse propósito, no diagnóstico, na elaboração de programas e em ações concretas. (ABREU, 2015, p. 4)
\end{abstract}

Em entrevista à Revista Sicoop (2015, p. 12), Abreu argumentou ainda que "o quadro atual dessas famílias rurais é de imensa pobreza e dispersão da renda, situação que o ministério pretende reverter, garantindo produtividade e corrigindo imperfeições de mercado". Em relação às imperfeições do mercado, afirmou que os agricultores de menor porte não possuem competitividade, pois pagam caro pelos insumos e vendem seus produtos a preços baixos. Portanto, segundo Abreu, o que falta aos agricultores "são oportunidades para assegurar a produção de forma sustentável".

O MDA, em certa medida e de igual modo, também incorporou em seus discursos a noção de classe média rural. Especialmente na gestão do ministro Pepe Vargas, ficaram evidentes as intenções de consolidar a agricultura familiar "como setor estratégico para o desenvolvimento econômico e social do país" e formar uma "enorme classe média rural", composta pela agricultura de base familiar (MDA, 2015, p. 1). Durante a gestão de Vargas, cabe ressaltar o lançamento da publicação "Superação da Pobreza e a Nova Classe Média no Campo" (NERI, MELO e MONTE, 2012), a qual buscou demonstrar a movimentação entre os estratos econômicos dos indivíduos residentes no meio rural. Na ocasião do lançamento, Vargas argumentou que

\footnotetext{
o livro é importante para todos que querem pensar desenvolvimento rural no Brasil dentro de uma estratégia de superação dos bolsões de pobreza que ainda existem. Essa nova classe média emerge a partir de um conjunto de políticas públicas construídas nos últimos anos que permitem que estejamos mais perto de um país sem miséria com justiça social (MDA, 2015a).
}

Note-se, portanto, uma convergência de interesses e discursos em ambos os ministérios a fim de fortalecer e incentivar a ampliação dos agricultores de porte médio, a chamada classe média rural. A despeito dos benefícios que a ampla oferta de crédito possa surtir, é importante observar que a ênfase comum das políticas de ambos os ministérios incide em dois pontos principais: fomentar a média produção a fim de sustentar condições para a produção e oferta de alimentos e, como estratégia, optam pelas vias do incremento produtivo com o financiamento de maquinário, equipamentos e implementos agrícolas. Ou seja, descortina-se, nesse cruzamento de referenciais, a ideia de desenvolvimento rural como sinônimo de aumento quantitativo das variáveis da relação do trabalho empregado, integração ao mercado e uso da tecnologia (GASQUES et al., 2010; VIEIRA FILHO, 2010).

Também é válido observar que embora subsistam dois referenciais setoriais para a agricultura, o debate acerca da classe média rural evidencia que ambos têm se alinhado ao referencial global de desenvolvimento que passou a prevalecer desde os anos 2000. A mobilidade das classes mais pobres em direção aos estratos intermediários passou a ser utilizada como uma marca do discurso político (uma imagem) do governo 
como um todo, tanto para o meio rural quanto para o urbano. Baseado principalmente na ampliação do consumo, esse referencial propunha a ideia de "nova classe média" como sinônimo de desenvolvimento e constituída principalmente por consumidores que expandiram sua capacidade de compra graças ao aumento da renda, associada aos altos níveis de empregabilidade e elevação do salário real ${ }^{5}$ (ABDALA, 2014). Nesse contexto, o referencial setorial da agricultura se ajusta a essa nova realidade a fim de compor políticas agrícolas e agrárias conforme a demanda de um mercado interno reconfigurado, especialmente em relação ao consumo de alimentos básicos. Logo, tanto em ciclos de crescimento econômico, como em cenários de crise político-econômica, o referencial de políticas em ambos os ministérios, inevitavelmente, ajustou-se conforme o novo plano macroeconômico.

\section{Interpretações acerca da classe média rural}

Com base nos cruzamentos de dados do Censo Agropecuário de 2006 (IBGE, 2009), a análise proposta por Alves e Rocha (2010), valendo-se da renda bruta auferida, divide os 5,2 milhões de estabelecimentos rurais em quatro classificações: até dois salários mínimos; de dois a dez salários mínimos; mais de dez salários mínimos e acima de 100 salários mínimos. Os autores entendem que cerca de um milhão de estabelecimentos situam-se no estrato médio, com renda bruta entre dois a dez salários mínimos mensais. Do total dos estabelecimentos rurais, $18,86 \%$ estaria situada em uma classe média e corresponderia por $11,08 \%$ do total da renda bruta. Essa classe média "tem condições de melhorar sua renda na agricultura, mas carece de ajuda no que diz respeito à extensão rural, crédito de custeio e investimentos, (...)" (ALVES e ROCHA, 2010, p. 288).

A subdivisão proposta pelos autores (IBID, 2010), também retoma a tese da inviabilidade agrícola de 3,8 milhões de estabelecimentos pertencentes à classe $\mathrm{D} / \mathrm{E}$. Segundo eles, os estabelecimentos com renda bruta até dois salários mínimos mensais $(72,96 \%)$ não possuem condições de desenvolverem-se por meio da produção agrícola. A esses agricultores, as políticas sociais cumpririam a tarefa de mantê-los no campo e evitariam o êxodo. Aos outros estabelecimentos, com renda superior a dez salários mínimos mensais, as políticas de alcance geral (macroeconômicas) dão conta de suas necessidades, juntamente com ações de melhoria em infraestrutura e "desobstrução" do acesso aos mercados.

Em outro trabalho, Alves, Souza e Rocha (2012) procuram demonstrar, também com base nos dados do Censo Agropecuário de 2006 (IBGE, 2009), que a elevada concentração do valor bruto produzido na agricultura decorre da falta de modernização dos pequenos produtores. Segundo os autores, existe um problema de difusão da tecnologia, pois ela não chega a milhões de estabelecimentos que contribuem "pouco" para a produção agrícola. Compreendem ainda que existe uma incapacidade administrativa por parte dos agricultores "malsucedidos" (IBID, 2012, p. 62) em administrar os dispêndios e a produtividade de todos seus fatores de produção.

Em estudo mais recente, Alves e Souza (2015) reforçam a hipótese de que a alta concentração da produção agropecuária em pouquíssimos estabelecimentos (maiores e mais capitalizados) se justifica pelo grau de tecnologia utilizada e não pela renda relacionada à terra e ao trabalho. Os autores entendem que o desenvolvimento passa pela intensificação do uso da tecnologia, elevando o valor da produção por hectare. Ademais, as imperfeições do mercado, segundo o texto, inibem a adoção da tecnologia

\footnotetext{
5 Para Neri, Melo e Monte (2012), a expansão da classe média, sobretudo a urbana, deu-se fundamentalmente pelo trabalho, consumo e produção.
} 
pelos pequenos produtores, deixando à margem da modernização 3,8 milhões de agricultores familiares.

A pesquisa proposta por Lopes et al. (2012) buscou identificar os estratos de renda líquida auferida nos estabelecimentos rurais. Os autores concluem que "os resultados confirmam que há uma importante classe média rural, provavelmente usuária de novas tecnologias e responsável pela modernização do setor." (IBID, 2012, p. 21). A classe média rural em questão compreende os estabelecimentos situados no intervalo de renda líquida mensal entre $\mathrm{R} \$ 947,00$ e $\mathrm{R} \$$ 4.083,00 (valores de 2006, conforme data de realização do Censo Agropecuário). No universo dos 5,2 milhões de estabelecimentos, 800 mil foram identificados como pertencentes à classe média rural, representando $15,46 \%$ do total dos estabelecimentos.

Nas classes $\mathrm{A} / \mathrm{B}$ e $\mathrm{C}$, a atividade agropecuária é o componente principal na formação da renda do estabelecimento, sendo responsável por $94 \%$ e $73 \%$, respectivamente. Na classe $\mathrm{D} / \mathrm{E}$, por outro lado, os programas sociais previdenciários e transferência de renda representam $52 \%$ da renda total, enquanto a atividade agropecuária gera apenas $30 \%$. Os mesmos autores afirmam, portanto, que a classe média rural é uma categoria "integrada ao mercado, faz uso de insumos modernos, utiliza primordialmente o trabalho familiar, mas é também contratadora de mão de obra temporária e permanente." Indicam que políticas de fomento à utilização de tecnologia produtiva ajudam a consolidar e ampliar esta classe. Por fim, considerando a situação das classes D/E, também sugerem a inviabilidade das políticas agrícolas e indicam políticas sociais focalizadas para o desenvolvimento deste estrato (LOPES et al., 2012, p.26).

Em estudo encomendado pelo Instituto Interamericano para Cooperação da Agricultura - IICA e realizado pelo Centro de Políticas Sociais da Fundação Getulio Vargas - CPS/FGV, Neri, Melo e Monte (2012) se propuseram a analisar as transformações recentes nos estratos sociais do mundo rural brasileiro. Comparando a trajetória de renda rural com a trajetória de renda do restante do país ${ }^{6}$, compreendem o aumento de um grande contingente de famílias ao estrato médio da população rural. Utilizando como foco de análise o contingente de indivíduos ${ }^{7}$ e valendo-se do cruzamento de microdados do Censo e Plano Nacional de Desenvolvimento PNAD/IBGE, os autores concluem que o estrato médio da população rural, identificado por eles como a nova classe média rural $^{8}$, cresceu acumuladamente $71,8 \%$ no período compreendido entre 2003 a 2009. A classe média rural, que representava $13,6 \%$ em 1992, passou de 20,6\% em 2003 a 35,4\% em 2009 e corresponderá, segundo estimativas, a 50\% em 2014 (NERI; MELO; MONTE, 2012).

Em termos absolutos, a classe $\mathrm{C}$ tornou-se dominante no sentido populacional: 9,1 milhões de indivíduos ascenderam das classes E/D para a classe média,

\footnotetext{
6 As principais mudanças no perfil da pobreza brasileira no período 2004-2009 decorrem: i) do crescimento econômico com distribuição via inclusão no mercado de trabalho; $i$ ) dos aumentos reais do salário mínimo, que levaram à quase erradicação da pobreza extrema e até da pobreza entre famílias com idosos; e iii) da expansão da cobertura e do valor das transferências focalizadas de renda, que foram, para várias famílias com alguma renda do trabalho, a via de escape da extrema pobreza ou da pobreza." (OSORIO et al., 2011).

${ }^{7}$ A análise centra-se na renda per capita individual, oriunda da divisão da renda total da família a que os indivíduos pertencem.

8 Ainda que o documento tenha utilizado majoritariamente a expressão "classes sociais", os autores argumentam aos sociólogos para "relaxarem", pois não estão se referindo a classes como operariado, burguesia ou capitalistas, e sim estratos econômicos (NERI; MELO; MONTE, 2012, p. 15). Portanto, a “expressão 'nova classe média' visa dar sentido positivo e prospectivo daquele que realizou - e continua a realizar - o sonho de subir na vida" (IBID, 2012, p. 15).
} 
correspondendo a 3,7 milhões de brasileiros. A classe D, por sua vez, representa $30,2 \%$ da população rural, correspondendo a 7,8 milhões de indivíduos. De 2003 a 2009, o índice proporcional da classe $\mathrm{E}$ reduziu $8,3 \%$, resultando num contingente de 8,2 milhões de indivíduos. Em relação às classes $\mathrm{A}$ e $\mathrm{B}$, no mesmo período, 83,4 mil pessoas ascenderam à classe $\mathrm{A}$ do meio rural, chegando a 231,5 mil pessoas, aumento de $57,9 \%$. Ascenderam à classe $\mathrm{B}$ a quantidade de 198,4 mil indivíduos, resultando em 416,7 mil indivíduos (IBID, 2012).

Segundo Neri, Melo e Monte (2012), em relação aos fatores que desencadearam tais mudanças, a renda do trabalho tem se mostrado menos determinante. Em 1992, os proventos do trabalho correspondiam a $81,33 \%$ da renda per capita no campo e passou a 66,5\% em 2009. Além disso, verifica-se uma diminuição da produção para subsistência. Em 2002, a pesquisa aponta que 19,45\% dos agricultores consumiam grande parte da produção agrícola. Em 2008, esse índice caiu para 15\%. Sumariamente, a agricultura de subsistência perde espaço para o trabalho formal em decorrência da expansão da agricultura empresarial. Isso sinaliza também a tendência de aumento da produtividade do campo, sendo refletida nas taxas de ocupação rural: em 2009, eram 19 milhões de ocupados no campo (74,2\% da população rural) enquanto, em 2003, havia 20,1 milhões de trabalhadores rurais $(77,4 \%)$.

Chama atenção o fato de que a contribuição do trabalho na renda diminuiu ao longo dos anos, ao passo que as transferências de renda apresentam-se gradativamente mais significativas. Ainda que o crescimento da renda total no campo, entre 2003 a 2009 , tenha sido maior que o crescimento da renda no restante do país (6,1\% contra $4,72 \%$ ), as transferências públicas de renda aumentaram ainda mais sua importância: $21,4 \%$ contra $12,9 \%$ em relação à média nacional (IBID, 2012). Percebe-se, portanto, que a reprodução social no meio rural mais pobre tem ficado mais dependente das transferências de renda, sobretudo de programas sociais focalizados como o Programa Bolsa Família.

Ademais, embora a quantidade de brasileiros extremamente pobres tenha reduzido nas últimas décadas, de acordo com Osorio et al. (2011), a distribuição relativa geográfica, etária, racial e educacional da pobreza, no entanto, não foi alterada. Os autores também evidenciam a excessiva dependência de políticas sociais compensatórias para o aumento das rendas. Isso indica que, embora as políticas agrícolas tenham sido adaptadas às especificidades da agricultura de base familiar, tais instrumentos não foram os principais fatores responsáveis pela mudança do quadro social no campo.

No caso do PRONAF, ainda que o programa tenha avançado continuamente no incremento de recursos (de $\mathrm{R} \$ 2,3$ bilhões na safra de 2002/2003 passou para $\mathrm{R} \$ 28,9$ bilhões na safra 2015/2016), segundo Bianchini (2015), o volume de investimentos permanece centrado nas regiões Sul e Sudeste do Brasil. Considerando que as camadas mais pobres da agricultura brasileira encontram-se na região Norte e Nordeste, esta emblemática política da Agricultura Familiar ainda necessita ampliar o seu universo de abrangência, incluindo desde os agricultores mais pobres e marginais aos mercados até os mais capitalizados e em todas as regiões brasileiras. Além disso, segundo Batista e Neder (2015), embora os investimentos do PRONAF tendam, indiretamente, a reduzir a pobreza via elevação da renda média e da redução da concentração de renda, não há um consenso sobre o efeito do programa na efetiva diminuição da desigualdade no campo.

O Plano Brasil Sem Miséria - PBSM, lançado em 2011, representou um alento frente ao contexto em que as políticas de inclusão produtiva foram pensadas. Por meio dos seus três eixos estratégicos (garantia de renda, acesso a serviços públicos e inclusão produtiva) o programa apostou na capacidade produtiva da parcela mais pobre da 
agricultura. As ações do programa envolvem acampados e assentados da reforma agrária, povos e comunidades tradicionais (MELLO, 2015). Em que pesem os avanços, o programa apresentou limitações e necessidade de aprimoramentos, sobretudo no que se refere ao incremento de investimentos, à expansão do número de famílias atendidas e às dificuldades de execução de ações interministeriais.

\section{Considerações acerca das implicações para a ação pública}

Seja pela análise dos indivíduos, seja pela ótica dos estabelecimentos rurais, as interpretações sustentam a tese de que a reprodução social do estrato médio acontece, majoritariamente, pelas vias de políticas agrícolas, ao passo que nos estratos mais pobres as políticas de transferência direta de renda têm maior relevância - o que é uma conclusão um tanto óbvia. Tais ideias têm embasado antigos questionamentos acerca da vocação produtiva dos agricultores mais pobres e pautado disputas políticas relacionadas à classe média rural. Como uma das consequências, também têm provocado controvertidas análises acerca da legitimidade da Agricultura Familiar enquanto categoria sociopolítica e público-alvo de determinadas políticas públicas.

Ainda que não seja a intenção deste artigo analisar a utilização do conceito de classe e, tampouco, o argumento de nova classe, é importante notar algumas objeções ao termo. De acordo com Abdala (2014) e Pochmann (2012), a distinção de classe observada nos estudos baseia-se, primeiramente, em subdivisões de substratos da renda e não a concepções de classes sociais propriamente ditas. Especialmente quando se refere ao aparecimento de uma nova classe social, essa expressão visa sustentar, arbitrariamente, uma relativa concepção de avanço do país e tenderia a obscurecer problemas estruturais e a vulnerabilidade conjuntural que refletem exatamente o oposto.

Segundo os autores, a ideia de nova classe média envolve, ao mesmo tempo, contradições e estratégias de um modelo de desenvolvimento nacional assentado na expansão do mercado de consumo em massa. Mesmo considerando os avanços na mudança social do país, é prudente utilizar o termo em contextos específicos (ABDALA, 2014; POCHMANN, 2012). As análises propostas pelos defensores da ideia de nova classe média, especialmente a rural, superestimam os dados econômicos na medida em que ocultam as especificidades e limitações das relações sociais de produção. Uma análise aproximada da concepção de nova classe média rural e dos fatores que visam caracterizá-la como uma "classe aspiracional", revelaria a incompletude de abrangência de políticas meramente creditícias e a timidez na diminuição das desigualdades de políticas de expansão agrícola conservadora e setorial.

Entender o campo brasileiro apenas como espaço de produção agrícola, ponto central entre as interpretações, revoga a existência de pautas relevantes, como a produção ecológica e orgânica, a questão agrária, a sucessão familiar, questões de gênero no meio rural, além, ainda, das especificidades de comunidades e povos tradicionais. Ao mesmo tempo, cria focos de incerteza quanto ao futuro de políticas relacionadas com a Segurança Alimentar e Nutricional, repercutindo sobre o acesso a mercados institucionais por parte da Agricultura Familiar. Portanto, faz tabula rasa com a diversidade dos modos de reprodução social do meio rural, formado por sujeitos e não apenas por produtores (PICOLOTTO, 2015), e abre mão de uma estratégia mais focada da redução das desigualdades socioeconômicas.

Isso tende a sustentar uma vulnerável promessa de integração ao mercado e uma questionável diminuição das desigualdades. Basta considerarmos o legado deixado pela "modernização desigual" (GONÇALVES NETO, 1997). A ideia de inserção ao mercado pela via da eficiência tecnológica, contraditoriamente, nega a uma grande 
massa de agricultores menos capitalizados essa mesma condição, renegando-os à permanente necessidade de políticas sociais focalizadas. Tal realidade estaria explicada, conforme as interpretações baseadas no incremento produtivo, ao aceitar a existência de algo como uma linha de corte que separaria os agricultores "com vocação produtiva" daqueles "sem vocação produtiva" (MATTEI, 2015). Ou seja, bastaria segmentar as políticas para o meio rural brasileiro conforme dois públicos-alvo: aqueles capazes de acessar políticas agrícolas e de incremento produtivo e aqueles, a camada mais pobre, a quem se permite acessar apenas políticas sociais.

Priorizar as políticas públicas ao médio produtor encobre a precária situação da maior parte dos agricultores brasileiros que estão situados nas classes de menor renda média e separados, à grande distância, dos agricultores com melhor condição de gerar renda. Contraditoriamente, afasta-se da proposta cunhada nos anos 1990, que previa a luta contra a invisibilidade dos agricultores pobres diante dos olhos do Estado e a diminuição da desigualdade estrutural nos meios de reprodução.

Para alguns autores, essas interpretações conduzem a questionamentos acerca da legitimidade das políticas continuarem destinando recursos aos "ineficientes", ao mesmo tempo em que sugerem a ineficácia do Estado em atender o "médio produtor rural". Navarro (2015), por exemplo, questiona a quantidade de recursos e a eficácia de determinadas políticas interministeriais que são direcionadas a agricultores que, segundo ele, não teriam condições de desenvolverem-se por vias da produção agrícola. De outro modo, usando o mesmo tipo de argumento, poder-se-ia igualmente questionar a legitimidade do Estado em priorizar os agricultores mais consolidados, tolhendo novamente a cidadania para a ampla maioria da população rural. Mas, aparentemente, nem todos incluem equidade e diversidade como parâmetros fundamentais para pensar e avaliar as estratégias de desenvolvimento. O referencial da classe média rural apenas reforça as velhas concepções modernizadoras tão amplamente criticadas no debate sobre desenvolvimento ao longo dos anos 1990 (MALUF, 2000).

Não é intenção entoar a polarização entre Agricultura Familiar versus agronegócio, pois esta ideia igualmente simplificadora, sustentada muitas vezes pelo maniqueísmo ideológico (SCHNEIDER, 2006), obscurece a diversidade (e as desigualdades) da produção agrícola no Brasil e tende a reduzir o debate apenas a questões quantitativas. Contudo, é necessário considerar que a agricultura brasileira está fundamentada em um dualismo produtivo constituído por modelos distintos e, não raras vezes, excludentes. Ao passo que a dinâmica da agricultura empresarial baseia-se no incremento da tecnologia e produtividade aplicadas, produção em larga escala e à integração aos mercados globais, a Agricultura Familiar considera a existência de diferentes modelos produtivos, tecnologias aplicadas, lógicas de trabalho e distintos modos de reprodução social, voltando-se principalmente ao abastecimento interno de alimentos.

Finalmente, cabe notar que o modo como a ideia de classe média vem sendo mobilizada na construção de referenciais de ação pública desconsidera a trajetória histórica de construção da Agricultura Familiar e do agronegócio como identidades sociopolíticas (BRUNO, 2009). Identidades que, se, por um lado, acentuam um dualismo excessivo em um meio rural muito mais heterogêneo, por outro, foram fundamentais para trazer à tona as discussões sobre as diferentes trajetórias de desenvolvimento rural, questionando o modelo econômico-produtivo herdado da modernização conservadora, centrado no ideário da produtividade agrícola, e que, atualmente, assume uma roupagem renovada nos debates sobre a classe média rural.

\section{REFERÊNCIAS}


ABDALA, P. R. Z. A organização do conceito "nova classe media", dialética do consumo e superexploração renovada do trabalho. Tese (Doutorado em

Administração), Universidade Federal do Rio Grande do Sul, Programa de PósGraduação em Administração, Porto Alegre, 2014.

ABRAMOVAY, R. Paradigmas do capitalismo agrário em questão. $2^{\mathrm{a}}$ Ed. Campinas: Hucitec, 1998.

ABREU, K. A importância das exportações. In: Revista de Política Agrícola, ano XXIV, n. 3, Brasília, jul./ago./set. 2015.

ABREU, K. O porquê de nossa empreitada à frente do Mapa. In: Revista de Política Agrícola, ano XXIV, n. 2, Brasília, abr./mai.jun. 2015a.

ALVES, E.; ROCHA, D. P. Ganhar tempo é possível? In: GASQUES, J. G.; VIEIRA FILHO, J. E. R.; NAVARRO, Z. A agricultura brasileira: desempenho recente, desafios e perspectivas. Brasília: IPEA/MAPA, 2010. p. 275-289.

ALVES, E.; SOUZA, G. S. Pequenos Estabelecimentos também enriquecem? Pedras e tropeços. In: Revista de Política Agrícola, ano XXIV, n. 3, Brasília, jul./ago./set. 2015.

ALVES, E.; SOUZA, G. S.; ROCHA, D. P. Lucratividade na agricultura. In: Revista de Política Agrícola, ano XXI, n. 2, Brasília, abr./mai./jun. 2012.

BATISTA, H. R.; NEDER, H. D. Efeitos do Pronaf Sobre a Pobreza Rural no Brasil (2001-2009). RESR. Piracicaba-SP, vol. 52, p. 147-166, fev. 2015.

BBC BRASIL. Reforma Agrária: entenda a disputa entre ministros Kátia Abreu e Patrus Ananias. Brasília, 2015. Disponível em: < http://www.bbc.com/portuguese/noticias/2015/01/150107_disputa_abreu_ananias_ms_1 $\mathrm{gb}>$. Acesso em: dez. 2015.

BIANCHINI, V. Vinte anos do PRONAF, 1995 - 2015: avanços e desafios. Brasília, DF: SAF/MDA, 2015.

BRASIL. Medida Provisória $n^{\circ} 726$, de 12 de maio de 2016. Altera e revoga dispositivos da Lei no 10.683, de 28 de maio de 2003, que dispõe sobre a organização da Presidência da República e dos Ministérios. Disponível em: < http://www.planalto.gov.br/ccivil_03/_Ato2015-2018/2016/Mpv/mpv726.htm >. Acesso em: jun. 2016.

BRASILa. Decreto $n^{\circ}$ 8.780, de 27 de maio de 2016. Transfere a Secretaria Especial de Agricultura Familiar e do Desenvolvimento Agrário para a Casa Civil da Presidência da República. Disponível em: < http://www.planalto.gov.br/CCIVIL_03/_Ato20152018/2016/Decreto/D8780.htm >. Acesso em: jun. 2016.

BRESSER-PEREIRA, L. C. A construção política do Brasil: sociedade, economia e Estado desde a Independência. 2a edição. São Paulo: Editora 34, 2015. 
BUAINAIN, A. M. et al. Sete teses sobre o mundo rural brasileiro. In: BUAINAIN, A.M. et al. O mundo rural no Brasil do século 21. Campinas: UNICAMP, 2014. p. 1159-1182.

BRUNO, R. Um Brasil ambivalente: agronegócio, ruralismo e relações de poder. Rio de Janeiro: Mauad, 2009.

CNA/FGV. Quem produz o que no campo: quanto e onde II. Censo Agropecuário 2006: resultados: Brasil e regiões. Brasília: CNA, 2010.

COSTA, F. A. Sete teses sobre o mundo rural brasileiro: antíteses. Revista da ABRA, Ed. especial, jul. 2013.

DELGADO, N. G. As relações entre a macroeconomia e a política agrícola.

Provocações para um debate interrompido. Estudos Sociedade e Agricultura. Rio de Janeiro, n. 14, p. 173-180, abr. 2000.

DELGADO, N. G. Política econômica, liberalização comercial e agricultura familiar: a experiência brasileira nas décadas de 1980 e 1990. In: LEITE, S. P. BONNAL, P. (Org.) Análise comparada de políticas agrícolas: uma agenda em transformação. Rio de Janeiro: Mauad X, 2011.

ERBER, F. As convenções de desenvolvimento no governo Lula: um ensaio de economia política. Revista de Economia Política, v. 31, n. 1, jan./mar. 2011.

ESTADÃO. Ao assumir Agricultura, Kátia Abreu promete gestão sem privilégio a empresa. Disponível em: <

http://politica.estadao.com.br/noticias/geral,aoassumiragriculturakatiaabreuprometegest aosemprivilegioaempresa,1615744 >. Acesso em: jun. 2016.

FAO/INCRA. Diretrizes de política agrária e desenvolvimento sustentável. Brasília, DF: FAO-INCRA, 1994.

FILIPPI, E. E. O desenvolvimento rural no Brasil: das políticas de Estado às políticas territoriais. In: LEITE, S. P. BONNAL, P. (Org.) Análise comparada de políticas agrícolas: uma agenda em transformação. Rio de Janeiro: Mauad X, 2011.

FONSECA, P. C. D.; CUNHA, A.; BICHARA, J. O Brasil na Era Lula: retorno ao desenvolvimentismo? Nova Economia. Belo Horizonte, v. 23, n. 2, p. 403-428, mai./ago. 2013.

FOUILLEUX, È. Analisar a mudança: políticas públicas e debates num sistema em diferentes níveis de governança. Estudos sociedade e agricultura, v. 19, n. 1, p. 88-125, 2011.

GASQUES, J. G.; et al. Produtividade total dos fatores e transformações da agricultura brasileira: análise dos dados dos censos agropecuários. In: GASQUES, J. G.; VIEIRA FILHO, J. E. R.; NAVARRO, Z. A agricultura brasileira: desempenho recente, desafios e perspectivas. Brasília: IPEA/MAPA, 2010. p. 275-289. 
GLOBO RURAL. Corte no orçamento impede realização do Censo Agropecuário. Disponível em: < http://g1.globo.com/economia/agronegocios/noticia/2016/04/corte-noorcamento-impede-realizacao-do-censo-agropecuario.html >. Acesso em: jun. 2016.

GLOBO RURALa. Kátia Abreu cria Secretaria da Interlocução e Mobilidade Social. Brasília, 2015. Disponível em: < http://revistagloborural.globo.com/Noticias/Agricultura/noticia/2015/01/katia-abreucria-secretaria-da-interlocucao-e-mobilidade-social.html >. Acesso em: dez. 2015.

GONÇALVES NETO, W. Estado e agricultura no Brasil: política agrícola e modernização econômica brasileira 1960-1980. São Paulo: HUCITEC, 1997.

GRAZIANO DA SILVA, J. A modernização conservadora: estrutura agrária, fronteira agrícola e trabalhadores rurais no Brasil. Rio de Janeiro: Zahar, 1992.

GRISA, C. Políticas públicas para a agricultura familiar no Brasil: produção e institucionalização das ideias. Tese (Doutorado em Ciências Sociais) - Programa de Pós-graduação de Ciências Sociais em Desenvolvimento, Agricultura e Sociedade/UFRRJ, 2012.

GRISA, C; SCHNEIDER, S. Três gerações de políticas públicas para a agricultura familiar e formas de interação entre sociedade e Estado no Brasil. In: GRISA, C. SCHNEIDER, S. Políticas Públicas de Desenvolvimento Rural no Brasil. Porto Alegre: Editora da UFRGS, 2015.

IBGE, Instituto Brasileiro de Geografia e Estatística. Censo agropecuário 2006. Rio de Janeiro: IBGE, 2009. Disponível em: < http://www.ibge.gov.br/home/estatistica/economia /agropecuaria/censoagro/brasil_2006/Brasil_censoagro2006.pdf > . Acesso em: dez. 2015.

LONG, N. Development sociology: actor perspectives. London: Routledge, 2001.

LOPES, I. V. et al. Perfis das classes de renda rural no Brasil. In: Revista de Política Agrícola, ano XXI, n. 2, Brasília, p. 21-27, abr./mai./jun. 2012.

MALUF, R. Atribuindo sentido(s) à noção de desenvolvimento econômico. Estudos Sociedade e Agricultura, v. 15, p. 53-86, 2000.

MAPA, Ministério da Agricultura, Pecuária e Abastecimento. Kátia Abreu: classe média rural não precisa de benesse, mas de oportunidade. Disponível em: < http://www.agricultura.gov.br/comunicacao/noticias/2015/03/katia-abreu--classe-mediarural-nao-precisa-de-benesse-mas-de-oportunidade > . Acesso em: dezembro de 2015.

MAPA, Ministério da Agricultura, Pecuária e Abastecimento. Mapa e Sebrae assinam Termo de Cooperação para capacitação de pequenos produtores. Disponível em: < http://www.agricultura.gov.br/politica-agricola/noticias/2015/03/mapa-e-sebraeassinam-termo-de-cooperacao-para-capacitacao-de-pequenos-produtores $>$. Acesso em: dezembro de 2015a. 
MAPA, Ministério da Agricultura, Pecuária e Abastecimento. Mapa fará busca ativa de produtores que podem ascender à classe média. Disponível em: <

http://www.agricultura.gov.br/comunicacao/noticias/2015/03/mapa-fara-busca-ativa-deprodutores-que-podem-ascender-a-classe-media >. Acesso em: dezembro de $2015 b$.

MAPA, Ministério da Agricultura, Pecuária e Abastecimento. Ministra apresenta programa de mobilidade social no campo à agência da ONU. Disponível em: < http://www.agricultura.gov.br/comunicacao/noticias/2015/10/ministra-apresentaprograma-de-mobilidade-social-no-campo-a-agencia-da-onu $>$. Acesso em: dezembro de $2015 \mathrm{c}$.

MAPA, Ministério da Agricultura, Pecuária e Abastecimento. Resultados de 2015, perspectivas para 2016: secretaria de relações internacionais do Agronegócio.

Disponível em: < http://www.agricultura.gov.br/arq_editor/file/acs/apresentacao1.pdf >. Acesso em: dez. 2015d.

MAPA, Ministério da Agricultura, Pecuária e Abastecimento. Plano Agrícola e Pecuário 2015/2016. Disponível em: < http://www.agricultura.gov.br/arq_editor/Cartilha_PAP_2015_16_Publicada.pdf >. Acesso em: dezembro de 2015e.

MATTEI, L. Considerações acerca de teses recentes sobre o mundo rural brasileiro. Revista de Economia e Sociologia Rural, São Paulo, v. 51, p. 105-124, fev. 2015.

MDA, Ministério do Desenvolvimento Agrário. Pepe Vargas toma posse como ministro do Desenvolvimento Agrário. Disponível em: < http://www.mda.gov.br/sitemda/radio$\mathrm{mda} /$ pepe-vargas-toma-posse-como-ministro-do-desenvolvimento-agr\%C3\%A1rio >. Acesso em: dezembro de 2015.

MDA, Ministério do Desenvolvimento Agrário. Estudo do NEAD identifica ascensão de uma nova classe média no meio rural. Disponível em: < http://www.mda.gov.br/sitemda/noticias/estudo-do-nead-identifica-ascens\%C3\%A3ode-uma-nova-classe-m\%C3\%A9dia-no-meio-rural >. Acesso em: dezembro de $2015 \mathrm{a}$.

MDA, Ministério do Desenvolvimento Agrário. Plano Safra 2015/2016: agricultura familiar alimentos saudáveis para o Brasil. Disponível em: < http://www.mda.gov.br/sitemda/sites/sitemda/files/user_arquivos_383/plano\%20safra\% 20cartilha.pdf >. Acesso em: dezembro de 2015b.

MDA, Ministério do Desenvolvimento Agrário. Produtividade é palavra de ordem na agricultura familiar, diz Lula. Disponível em: <

http://www.mda.gov.br/sitemda/noticias/produtividade-e\%CC\%81-palavra-de-ordemna-agricultura-familiar-diz-lula $>$. Acesso em: dezembro de 2015c.

MELLO, J. (org.) A inclusão produtiva rural no Brasil Sem miséria: o desafio da superação da pobreza no campo. Cadernos de Estudos Desenvolvimento Social em Debate. Brasília, DF: MDS, n. 23, set. 2015. 
MIELITZ NETTO, C. A. A agricultura familiar no contexto das políticas públicas brasileiras. In: MANZANAL, M.; NEIMAN, G. Las agriculturas familiares del Mercosur. Ediciones Ciccus, 2010.

MIELITZ NETTO, C. A. Política agrícola brasileira, sua adequação e sua funcionalidade nos vários momentos do desenvolvimento nacional. In: LEITE, S. P. BONNAL, P. (Org.) Análise comparada de políticas agrícolas: uma agenda em transformação. Rio de Janeiro: Mauad X, 2011.

MULLER, P.; SUREL, Y. A análise das políticas públicas. Pelotas, EDUCAT, 2004.

NAVARRO, Z. A agricultura familiar no Brasil: entre a política e as transformações da vida econômica. In: GAQUES, J. G.; VIEIRA FILHO, J. E. R.; NAVARRO, Z. (Org.). A agricultura brasileira: desempenhos, desafios e perspectivas. Brasília, DF: IPEA, 2010. p. 185-209.

NAVARRO, Z. "Agricultura familiar" e a nova fase da agricultura. In: GRAZIANO, X.; NAVARRO, Z. Novo mundo rural: a antiga questão agrária e os caminhos futuros da agropecuária do Brasil. São Paulo: Editora Unesp, 2015.

NAVARRO, Z. História concisa da agricultura brasileira: do pós-guerra aos nossos dias. In: GRAZIANO, X.; NAVARRO, Z. Novo mundo rural: a antiga questão agrária e os caminhos futuros da agropecuária do Brasil. São Paulo: Editora Unesp, 2015a.

NERI, M. C.; MELO, L. C. C.; MONTE, S. R. S. Superação da pobreza e a nova classe média no campo. Rio de Janeiro: Editora FGV, 2012. 312p.

NIEDERLE, P. A. Revisitando o conceito de produção simples de mercadorias. In: ENCONTRO NACIONAL DE GEOGRAFIA AGRÁRIA, 19., 2009, São Paulo. Anais... São Paulo: ENGA, 2009. p. 1-25.

NIEDERLE, P. A.; GRISA, C. Ideias e valores: análise da ação pública a partir das interfaces entre a abordagem cognitiva e a economia das convenções. Política e Sociedade, Florianópolis, v. 12, n. 23, p. 97-136, jan./abr. 2013.

OSORIO, R. G. et al. Perfil da pobreza no Brasil e sua evolução no período 2004-2009. Textos para discussão. Brasília, DF: IPEA, ago. 2011.

PICOLOTTO, E. L. Reconhecimento da agricultura familiar e as disputas pela classe média rural. Revista Espaço Acadêmico, n. 128, jan. 2012.

PICOLOTTO, E. L. Os atores da construção da categoria agricultura familiar no Brasil. RESR, Piracicaba-SP, v. 52, p. 63-84, fev. 2015.

POCHMANN, M. Nova classe media? O trabalho na base da pirâmide social brasileira. São Paulo: Boitempo, 2012.

REVISTA EXAME. Temos de formar uma classe média rural, diz Kátia Abreu. São Paulo, 2015. Disponível em: < http://exame.abril.com.br/revista- 
exame/edicoes/109202/noticias/ temos-de-formar-uma-classe-media-rural >. Acesso em: dez. 2015.

REVISTA SICOOB. Prosperidade no campo. Ano 6, abr./mai./jun. 2015.

SABOURIN, Eric. Que política pública para a agricultura familiar no segundo governo Lula? Sociedade e Estado, Brasília, v. 22, n. 3, p. 715-751, set./dez. 2007.

SCHNEIDER, S. (Org.). Diversidade da agricultura familiar. Porto Alegre: UFRGS, 2006.

SCHNEIDER, S. Situando o desenvolvimento rural no Brasil: o contexto e as questões em debate. Rev. Economia Política, São Paulo, v. 30, n. 3, p. 511-531, jul./set. 2010.

WANDERLEY, M. N. B. O mundo rural como espaço de vida: reflexões sobre a propriedade da terra, agricultura familiar e ruralidade. Porto Alegre: UFRGS, 2009.

WILKINSON, J. Agronegócios e agricultura familiar: entre confronto e diálogo. In: WILKINSON, J. Mercados, redes e valores. Porto Alegre: UFRGS, 2008.

VIEIRA FILHO, J. E. R. Trajetória tecnológica e aprendizado no setor agropecuário. In: GASQUES, J. G.; VIEIRA FILHO, J. E. R.; NAVARRO, Z. A agricultura brasileira: desempenho recente, desafios e perspectivas. Brasília: IPEA/MAPA, 2010. p. 275-289.

Submetido em 12/04/2016

Aprovado em 23/05/2016

\section{Denis Soldera}

Mestrando no Programa de Pós-Graduação em Desenvolvimento Rural - PGDR da Universidade Federal do Rio Grande do Sul - UFRGS. Grupo de Estudos e Pesquisas em Agricultura Familiar e Desenvolvimento Rural (GEPAD).

E-mail: denis.soldera@gmail.com

\section{Paulo Andre Niederle}

Professor dos Programas de Pós-Graduação em Desenvolvimento Rural - PGDR e Sociologia - PPGS da Universidade Federal do Rio Grande do Sul - UFRGS. Grupo de Estudos e Pesquisas em Agricultura Familiar e Desenvolvimento Rural - GEPAD.

E-mail: pauloniederle@gmail.com 